\title{
Using an in-vivo syngeneic spontaneous metastasis model identifies ID2 as a promoter of breast cancer colonisation in the brain
}

Magdalena Kijewska ${ }^{1,2}$, Carmen Viski ${ }^{1}$, Frances Turrell ${ }^{1}$, Amanda Fitzpatrick ${ }^{1}$, Antoinette van Weverwijk ${ }^{1,3}$, Qiong Gao ${ }^{1}$, Marjan Iravani ${ }^{1}$ and Clare M. Isacke ${ }^{1 *}$ (D)

\begin{abstract}
Background: Dissemination of breast cancers to the brain is associated with poor patient outcome and limited therapeutic options. In this study we sought to identify novel regulators of brain metastasis by profiling mouse mammary carcinoma cells spontaneously metastasising from the primary tumour in an immunocompetent syngeneic host.

Methods: 4T1 mouse mammary carcinoma sublines derived from primary tumours and spontaneous brain and lung metastases in BALB/C mice were subject to genome-wide expression profiling. Two differentially expressed genes, Id 2 and Aldh3a1, were validated in in-vivo models using mouse and human cancer cell lines. Clinical relevance was investigated in datasets of breast cancer patients with regards to distant metastasis-free survival and brain metastasis relapse-free survival. The role of bone morphogenetic protein (BMP)7 in regulating /d2 expression and promoting cell survival was investigated in two-dimensional and three-dimensional in-vitro assays.

Results: In the spontaneous metastasis model, expression of $I d 2$ and Aldh3al was significantly higher in 4T1 brain-derived sublines compared with sublines from lung metastases or primary tumour. Downregulation of expression impairs the ability of cells to colonise the brain parenchyma whereas ectopic expression in 4T1 and human MDA-MB-231 cells promotes dissemination to the brain following intracardiac inoculation but has no impact on the efficiency of lung colonisation. Both genes are highly expressed in oestrogen receptor (ER)-negative breast cancers and, within this poor prognosis sub-group, increased expression correlates with reduced distant metastasis-free survival. ID2 expression also associates with reduced brain metastasis relapse-free survival. Mechanistically, BMP7, which is present at significantly higher levels in brain tissue compared with the lungs, upregulates ID2 expression and, after BMP7 withdrawal, this elevated expression is retained. Finally, we demonstrate that either ectopic expression of ID2 or BMP7-induced ID2 expression protects tumour cells from anoikis.

Conclusions: This study identifies ID2 as a key regulator of breast cancer metastasis to the brain. Our data support a model in which breast cancer cells that have disseminated to the brain upregulate ID2 expression in response to astrocyte-secreted BMP7 and this serves to support metastatic expansion. Moreover, elevated ID2 expression identifies breast cancer patients at increased risk of developing metastatic relapse in the brain.
\end{abstract}

Keywords: Breast cancer metastasis, Brain metastasis, Spontaneous metastasis, Mouse models, 4T1, ID2, ALDH3A1, Intracranial, Intracardiac

\footnotetext{
* Correspondence: clare.Isacke@icr.ac.uk

${ }^{1}$ The Breast Cancer Now Toby Robins Research Centre, The Institute of

Cancer Research, 237 Fulham Road, London SW3 6JB, UK

Full list of author information is available at the end of the article
}

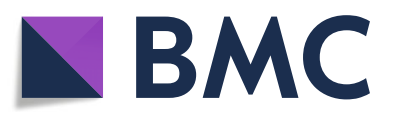

(c) The Author(s). 2019 Open Access This article is distributed under the terms of the Creative Commons Attribution 4.0 International License (http://creativecommons.org/licenses/by/4.0/), which permits unrestricted use, distribution, and reproduction in any medium, provided you give appropriate credit to the original author(s) and the source, provide a link to the Creative Commons license, and indicate if changes were made. The Creative Commons Public Domain Dedication waiver (http://creativecommons.org/publicdomain/zero/1.0/) applies to the data made available in this article, unless otherwise stated. 


\section{Introduction}

Metastasis of breast cancer to the brain represents an area of high un-met medical need; $15-30 \%$ of patients with metastatic breast cancer will develop brain metastases, and the brain is the first site of metastasis in $7-16 \%$ of metastatic patients [1]. Survival upon a brain metastasis diagnosis is 4 months to 2 years, with worse prognosis for patients with triple negative (TN) breast cancer or multiple brain lesions, and better prognosis for those with oestrogen receptor-positive $\left(\mathrm{ER}^{+}\right)$or human epidermal growth factor receptor 2-positive $\left(\right.$ HER $2^{+}$) disease or a single brain metastasis [2,3]. The incidence of brain metastasis for breast and other cancers has been increasing, likely due to improved imaging and other diagnostic technologies and more effective systemic and targeted therapies which prolong patient survival by controlling extra-cranial disease. However, agents that control systemic disease often have poor brain penetrance resulting in failure to control disease progression $[4,5]$.

Over the past decade there has been significant progress in understanding the mechanisms underpinning brain metastasis, including the identification of key molecular events required for successful tumour cell transmigration across the blood-brain barrier and for avoiding apoptosis once the cells have reached the brain parenchyma $[1,5-$ 8]. However, these studies have relied heavily on directly inoculating tumour cells into the left ventricle of the heart and on the use of human cell lines in immunocompromised mice. Such a scenario fails to recapitulate the clinical setting where low numbers of circulating tumour cells will encounter different organs and have to avoid immune attack [7]. To better mimic human disease, we used a model of spontaneous metastasis of 4T1 mouse mammary carcinoma cells in syngeneic, immunocompetent BALB/c mice. We have profiled 4T1 sublines derived from primary tumours and from tumour cells that had disseminated to the lungs and brain and performed in-vivo validation experiments and assessment of clinical datasets. Using this approach, we identified a role for ID2 and $A L D H 3 A 1$ in promoting metastatic colonisation and for ID2 in promoting brain-specific metastasis.

\section{Methods}

\section{Cells and reagents}

4T1 cells were obtained from the American Type Culture Collection (ATCC), tagged with luciferase using lentiviral particles expressing Firefly luciferase (Amsbio), and grown in Dulbecco's modified Eagle's medium (DMEM) supplemented with $10 \%$ fetal bovine serum (FBS). MDA-MB231-Luc cells were obtained from Sibtech and grown in DMEM supplemented with 10\% FBS. Where indicated, 4T1-Luc cells were transduced with lentiviral particles expressing H2B-mRFP as previously described [9] and $\mathrm{RFP}^{+}$cells enriched by fluorescence-activated cell sorting
(FACS). Cells were short tandem repeats (STR) tested regularly using the StemElite ID system (Promega). Both cell types were routinely tested for mycoplasma and used within 10 passages after resuscitation. Mouse astrocytes were purchased from ScienCell and maintained in astrocyte basal medium supplemented with FBS and astrocyte growth supplement. Recombinant human transforming growth factor (TGF) $\beta-1$ and bone morphogenetic protein (BMP)7 were purchased from R\&D systems. Details of short hairpin RNA (shRNA) lentiviruses, full length open reading frame (ORF) clone expression systems, quantitative reverse-transcription polymerase chain reaction (RT-qPCR) reagents, and antibodies used in this study are provided in Additional file 1 (Tables S1-S4).

For shRNA knockdown of Id2 or Aldh3a1, $5 \times 10^{4}$ 4T1-Luc cells were transduced with lentiviral particles (Sigma; Mission transduction particles) at a multiplicity of infection (MOI) of 2 . At $24 \mathrm{~h}$ post-transduction, the medium was replaced with fresh medium containing $10 \%$ FBS. Stably transduced cells were selected in $2.5 \mu \mathrm{g} /$ $\mathrm{mL}$ puromycin for two passages.

For ectopic expression of Id2 or Aldh3a1, $8 \mu \mathrm{g}$ of bicistronic mammalian expression vector pReceiverLv166 mCherry vector with or without full length ORF for mouse Id2 (EX-Mm03201-Lv166) or Aldh3a1 (EXMm28326-Lv166-GS) purified plasmid, $4 \mu \mathrm{g}$ of packaging plasmid psPAX2, and $1.5 \mu \mathrm{g}$ envelope plasmid pMD2.G were co-transfected into the HEK293T cells using OptiMEM and Lipofectamine 2000. At $48 \mathrm{~h}$ posttransfections, virus-containing medium was collected and used to directly infect 4T1-Luc or MDA-MB-231Luc cells. At $72 \mathrm{~h}$ post-infection, cells were FACS sorted to enrich for mCherry-positive cells.

\section{In-vivo experiments}

All animals were monitored on a daily basis by staff from the ICR Biological Service Unit for signs of ill health.

To isolate tumour cells disseminated to metastatic sites for gene expression profiling, $1 \times 10^{4} 4 \mathrm{~T} 1$-Luc cells in $50 \mu \mathrm{L}$ phosphate-buffered saline (PBS) were inoculated subcutaneously into 6- to 8-week-old female $\mathrm{BALB} / \mathrm{c}$ mice. Once primary tumours reached the maximum (mean diameter $\geq 15 \mathrm{~mm}$ ) allowable size, the mice were sacrificed. Primary tumours, lungs, and brains were harvested at necropsy. Primary tumours were individually cut into small pieces, homogenized using a McIlwain Tissue Chopper (Campden Instruments), and digested in L-15 medium containing $3 \mathrm{mg} /$ $\mathrm{mL}$ collagenase type $\mathrm{I}$ at $37^{\circ} \mathrm{C}$ for $1 \mathrm{~h}$, followed by digestion with $0.025 \mathrm{mg} / \mathrm{mL}$ DNase 1 at $37^{\circ} \mathrm{C}$ for $5 \mathrm{~min}$. After erythrocyte lysis using Red Blood Cell Lysing Buffer (Sigma), the cell suspension was plated into a $10-\mathrm{cm}$ dish in $10 \mathrm{~mL}$ DMEM plus 10\% FBS. Individual lungs and brains were placed in $1 \mathrm{~mL}$ PBS on a $40-\mu \mathrm{m}$ sieve 
in a 6-cm plate, mechanically dissociated by pushing through the sieve, and cultured in $2 \mathrm{~mL}$ DMEM plus $10 \%$ FBS in $6-\mathrm{cm}$ dishes. When primary tumour-, brainand lung-derived $4 \mathrm{~T} 1$ colonies were visible, cells were passaged 3-4 times before RNA was extracted from individual sublines for gene expression profiling.

For experimental metastasis assays, 6- to 8-week-old female BALB/c or NOD SCID gamma (NSG) mice were inoculated with 4T1-Luc or MDA-MB-231 cells. For intracranial inoculations, mice were anaesthetised with isoflurane and injected with $1 \times 10^{4} 4 \mathrm{~T} 1$-Luc cells in $5 \mu \mathrm{L}$ PBS into the brain at a rate of $2.5 \mu \mathrm{L}$ tumour cells $/$ min using a stereotaxic frame with pre-defined co-ordinates relative to bregma ( $x=-2 \mathrm{~mm}, y=1 \mathrm{~mm}, z=-2 \mathrm{~mm}$ ). At post-mortem, brains were in-vivo imaging system (IVIS) imaged ex-vivo, fixed in $4 \%$ paraformaldehyde for $24 \mathrm{~h}$, and paraffin embedded. For intracardiac inoculation, mice were anaesthetized with isoflurane and $5 \times 10^{4} \quad 4 \mathrm{~T} 1$ (BALB/c mice) or $3 \times 10^{5}$ MDA-MB-231 cells (NSG mice) were injected into the left ventricle of the heart in $100 \mu \mathrm{L}$ PBS. At the end of the experiment, post-mortem tissues were IVIS imaged ex-vivo, fixed in $4 \%$ paraformaldehyde for $24 \mathrm{~h}$, and either paraffin embedded or frozen.

For RNA expression analysis of freshly isolated cells, 4T1-Luc-RFP cells were inoculated either subcutaneously $\left(5 \times 10^{5}\right.$ cells), intravenously via the lateral tail vein $\left(1 \times 10^{5}\right.$ cells $)$ or, as described above, intracranially $(1 \times$ $10^{4}$ cells). Then, 9-13 days later, primary tumours, lungs, and brains were collected. Primary tumours were dissociated using the MACS mouse tumour dissociation kit (Miltenyi Biotec), and lungs and brain were dissociated using the MACS lung dissociation kit. RFP-positive 4T1-Luc cells were FACS sorted directly into RLT lysis buffer (Qiagen) for RNA extraction.

For fluorescent imaging of brain sections, whole $4 \%$ paraformaldehyde-fixed brains were submerged in 30\% sucrose in PBS at $4{ }^{\circ} \mathrm{C}$ before moulding in OCT and freezing in dry ice plus isopentane. The frozen brain was cryostat sectioned at $20-\mu \mathrm{m}$ intervals. For imaging of mCherry-positive cells, sections were defrosted, washed in PBS, DAPI stained, mounted, and scanned using the Vectra 3.0 automated quantitative pathology imaging system (Perkin Elmer).

For histological and immunohistochemical analysis, formalin-fixed paraffin-embedded (FFPE) brain sections were haematoxylin and eosin $(\mathrm{H} \& \mathrm{E})$ or antibody stained and scanned on the NanoZoomer digital slide scanner (Hamamatsu). Tumour burden was quantified using Image J in a coronal section taken at the median level through each brain.

\section{Gene expression profiling}

RNA extracted (RNeasy Mini kit) from independently isolated 4T1 sublines derived from primary tumour ( $\mathrm{T}$, $n=3)$, brain metastases (B, $n=4)$, and lung metastases $(\mathrm{L}, \quad n=3)$ was subjected to microarray analysis on Mouse WG-6 v2.0 expression BeadChips (Illumina, San Diego, CA, USA). RNA amplification, labelling, and hybridization were performed according to the manufacturer's instructions at Cambridge Genomic Services. The raw data were extracted using GenomeStudio Software and was processed in $\mathrm{R}$ using the lumi package (http://www.bioconductor.org). In brief, data were: 1) filtered to remove any non-expressed probes (detection $p>0.01$ ) across samples involved in a given group comparison; 2) transformed using the variance-stabilising transformation; and 3) normalised using the robust spline normalisation method.

Sample relations were estimated using unsupervised hierarchical clustering (Euclidean distance, average linkage) based on 17,550 probes. Two-sample $t$ tests (with random variance model) were used to identify differentially expressed genes between 1 ) $\mathrm{L}$ and $\mathrm{T}, 2$ ) $\mathrm{B}$ and $\mathrm{L}$, and 3) B and T sublines using the BRB-Array Tools (https:// brb.nci.nih.gov/BRB-ArrayTools) with a threshold of parametric $p$ value $<0.001$. When multiple probes were mapped to the same gene, the most variable probe measured by interquartile range (IQR) across the samples was selected to represent the gene. Gene expression data are deposited at GEO with the accession number GSE110101.

\section{RT-qPCR}

RNA from cultured cells or whole mouse tissue or from freshly isolated tumour cells was extracted using the RNeasy Mini kit or the RNeasy Plus Micro kit, respectively, according to the manufacturer's instructions. RNA was eluted in 10-30 $\mu \mathrm{L}$ nuclease-free water. The RNA concentration was measured in a $1-\mu \mathrm{L}$ sample using the Qubit2.0 Fluorometer (Invitrogen) or the ND-1000 Spectrophotometer (Nanodrop). cDNA was produced by reverse transcribing 150-500 ng RNA using the QuantiTect reverse transcription kit (Qiagen) or SuperScript IV First-Strand Synthesis System (Invitrogen) according to the manufacturer's instruction. qPCR was performed on $11.25 \mathrm{ng}$ cDNA $(4.5 \mu \mathrm{L})$ with $0.5 \mu \mathrm{L}$ Taqman Gene Expression Assay probe and $5 \mu \mathrm{L} 2 \times \mathrm{qPCR}$ Master mix per well. Relative quantification was performed using QuantStudio Real-time PCR software or on an ABI Prism 7900 HT sequence detection system. Each reaction was performed in triplicate. Data were analysed using QuantStudio Real-time PCR or SDS 2.2.1 software, and relative expression levels were normalised, unless otherwise stated, to $B 2 m / B 2 M$ or Gapdh endogenous control, with a confidence interval of $95 \%$ for all assays.

\section{Cell based assays}

For spheroid growth assays, $7.5 \times 10^{2}$ cells/well were sorted into U-bottom low adherence 96-well plates (Corning) in 
DMEM containing 2\% FBS. At 7 days post-seeding, the viability of the cells in the three-dimensional tumour spheroids was assessed using CellTiter-Glo (Promega) with luminescence quantified using a Victor X5 plate reader.

For the anoikis assay, $5 \times 10^{4}$ cells/well were seeded into low-adherence six-well plates (Costar) in DMEM containing $2 \% \mathrm{FBS}$. At $24 \mathrm{~h}$ post-seeding, cells were stained with Annexin V-APC/PI Apoptosis Detection Kit (eBioscience) and analysed using a BD Biosciences LSRII flow cytometer with FACSDIVA and FlowJo software. Cell viability was measured as a proportion of healthy (Annexin-negative, PI-negative) cells.

\section{Human and mouse datasets}

The expression levels of $I D 2$ and $A L D H 3 A 1$ and their relation to the receptor status of ER, progesterone receptor (PR), and HER2 were assessed for breast cancer samples in The Cancer Genome Atlas (TCGA) [10]. The expression level of BMP7 in non-tumour-bearing mice was assessed in 1) brain astrocytes, neurons, and microglia using the Srinivasan et al. RNAseq dataset [11], and 2) brain microglia and astrocytes using the Kamphuis et al. microarray dataset [12]. Clinical significance (distant metastasis-free survival) of ID2 and $A L D H 3 A 1$ expression in $\mathrm{ER}^{-}$breast cancers was assessed using publicly available data from Gyorffy et al. [13]. Associations of ID2 and ALDH3A1 mRNA levels and brain metastasis were tested in four breast cancer datasets (GSE2034, GSE2603, GSE12276, and GSE14020), normalized by MAS5.0, $\log _{2}$ transformed, and batch corrected. The tumour subtype information was published in a previous study [14]. The datasets contained $104 \mathrm{ER}^{-}$breast cancer patients who either had no metastatic relapse $(n=71)$ or brain-only metastatic relapse $(n=33)$. Brain metastasis relapse-free survival analysis was performed using the upper tertile of gene expression to dichotomise the breast cancers.

To assess the expression of ID2 in primary breast cancers and breast cancer brain metastases, the datasets described in Schulten et al. (GSE100534) [15] and Harrell et al. (GSE26338) [16] were retrieved. GSE26338 contains data deposited from seven different platforms. Samples run on the GPL5325 platform were enriched for metaplastic breast cancers and were therefore excluded.

\section{Statistical analysis}

Statistical analyses were performed using GraphPad Prism 7. Unless stated otherwise, data represent the mean values \pm standard error of the mean (SEM). Where the groups followed normal distribution and had equal variances, the significance of the differences of the groups was tested using either unpaired Student's $t$ test (two groups) or one-way analysis of variance (ANOVA; multiple groups) followed by Bonferroni post-hoc testing for correcting multiple comparisons. If groups did not follow a normal distribution, non-parametric Mann-Whitney (two groups) or Kruskal-Wallis (multiple groups) tests were used. Statistical significance was defined as * $p$ $<0.05,{ }^{* * *} p<0.01$, and ${ }^{* * * *} p<0.001$.

\section{Results}

Increased Id 2 and Aldh $3 a 1$ expression in breast cancer cells disseminated to the brain

To establish a model that more closely mimics the clinical scenario, 4T1 mouse mammary carcinoma cells were grown as primary tumours in syngeneic BALB/c mice. At the termination of the experiment, brains, lungs, and primary tumours were individually dissociated to derive $4 \mathrm{~T} 1$ sublines isolated from different sites. Using this approach, tumour cells were detected in the brains of $\sim 25 \%$ of the mice, an incidence that is lower than with intracardiac inoculation but which represents a model in which cells have followed the full metastatic cascade. Unsupervised hierarchical clustering of independent 4T1 sublines isolated from primary tumours $(n=3)$, lungs $(n=3)$, and brains $(n=4)$ revealed a separation of the brain-derived sublines from the lung and primary tumour cultures (Fig. 1a). Similarly, two-sample $t$ tests of 4T1 sublines (Fig. 1b) identified differentially expressed genes $(p<0.001)$ as follows: 162 genes differentially expressed between lung and primary tumour sublines (122 upregulated in L, 40 downregulated in L), 536 genes differentially expressed between brain and lung sublines (248 upregulated in B, 288 downregulated in B), and 786 genes differentially expressed between brain and primary tumour sublines (379 upregulated in B, 407 downregulated in B). Overall, the tests revealed a closer relationship between the primary tumour and lung sublines than between the brain sublines and either the tumour or lung sublines. A heat map displaying the 186 highly significantly expressed genes (absolute fold change $\geq 2.0, p<0.001$ ) between $\mathrm{L}$ and $\mathrm{T}$, between $\mathrm{B}$ and $\mathrm{L}$, or between $B$ and $T$ is provided in Fig. 1c, with a higher power image showing all differentially expressed gene names in Additional file 1 (Figure S1).

A shortlist of potential enhancers of brain metastasis was generated by identifying upregulated genes (absolute fold change $\geq 2.0, p<0.001$ ) in $\mathrm{B}$ versus $\mathrm{T}$ and $\mathrm{B}$ versus $\mathrm{L}$, but not between $\mathrm{L}$ and $\mathrm{T}(n=29$ genes; Additional file 1: Figure S2). Of these, five genes (Aldh3a1, Bdh2, Gnnmb, Id2, and Uap1l1) were selected for further validation based on a combination of literature searching and ingenuity pathways analysis. RT-qPCR was performed using RNA isolated from the profiled sublines (B1-B4, L1-L3, T1-T3) plus from five or six independently isolated brain metastasis sublines. Id 2 and Aldh $3 a 1$ were consistently upregulated in the independent brainderived sublines compared with both the primary tumour and lung-derived sublines (Fig. 1d). Moreover, 
a

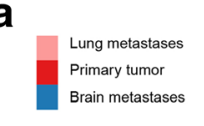

b
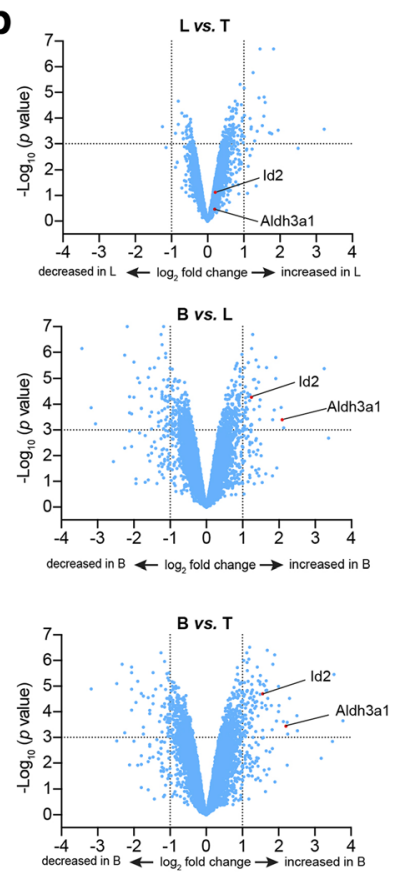

e
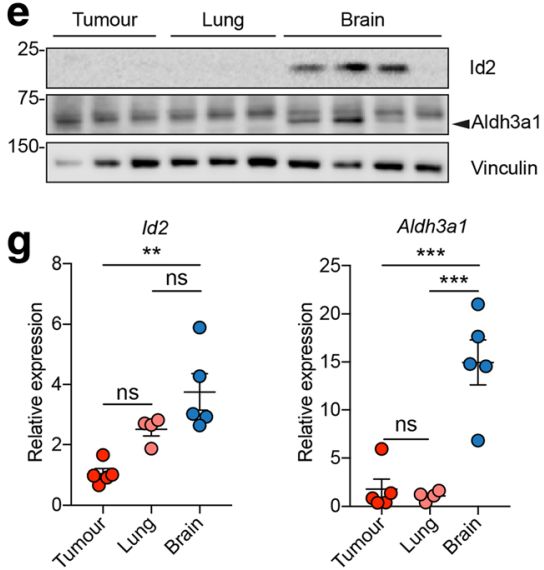

C
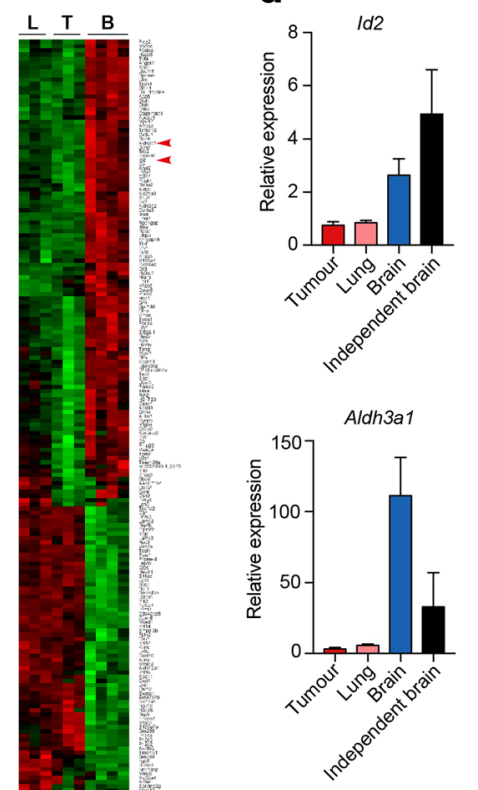

f

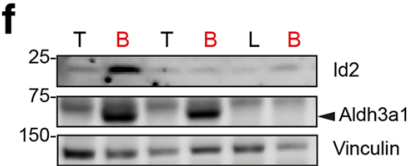

$\begin{array}{lllllllllll} & \text { L } & \text { B } & \text { L } & \text { B } & \text { T } & \text { B }\end{array}$

Fig. 1 Gene expression profiling of 4T1 sublines from primary and metastatic sites. 4T1-Luc sublines independently isolated from primary tumours (T1-T3), lungs (L1-L3), or brains (B1-B4) were subject to gene expression profiling. a Unsupervised hierarchical clustering (Euclidean distance, average linkage) estimating the relation of the independent 4T1 sublines based on 17,550 probes. b Volcano plots showing differentially expressed

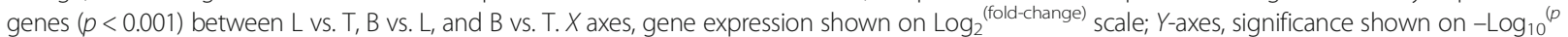
value) scale. c Heat map (Pearson, ward.D2) of 186 genes (with official mouse gene symbol) differentially expressed between $B$ and $T$, between $B$ and $L$, or between $L$ and $T$ sublines with an absolute fold change $\geq 2.0, p<0.001$. Sublines are in the same order as in Fig. 1 a. Arrowheads indicate Id2 and Aldh3a1. See Additional file 1 (Figure S1) for a higher power image including gene names. $\mathbf{d}$ RT-qPCR analysis of Id2 and Aldh3a1 expression in sublines used in a, plus five or six independently isolated brain metastasis sublines. e,f Immunoblotting of (e) sublines used in a or (f) independently isolated 4T1-Luc T, L, and B sublines. Molecular size makers are in kDa. Arrows indicates the lower migrating Aldh3a1 protein. g 4T1-Luc-RFP cells were isolated from primary tumours, lungs, and brains of BALB/C mice inoculated subcutaneously, intravenously, or intracranially, respectively. Expression of $/ d 2$ and Aldh3a1 was analysed by RT-qPCR, $n=5$ mice per group. Mean \pm SEM. ${ }^{* *} p<0.01$, *** $p<0.001$, oneway ANOVA. ns not significant 
elevated Id2 and Aldh3a1 protein levels were detected by immunoblotting in the original brain-derived sublines (Fig. 1e) as well as in the independent sublines isolated from the brains of tumour-bearing mice (Fig. 1f).

Finally, to confirm that the expression of $I d 2$ and Aldh3a1 is upregulated in tumour cells colonising the brain in-vivo, 4T1 tumour cells were freshly isolated from the brains, lungs, and primary tumours and immediately analysed by RT-qPCR. Consistent with our previous findings (Fig. 1b), both $I d 2$ and Aldh $3 a 1$ were significantly upregulated in tumour cells isolated from the brain compared with the primary tumour, with a higher expression of these genes in the brain-derived cells compared with those isolated from the lungs (Fig. 1g).

ID2 (inhibitor of differentiation 2 or inhibitor of DNA binding 2) is a helix-loop-helix (HLH)-containing protein that lacks a DNA-binding domain and is one of the four members of the ID family (ID1-ID4). Id proteins dimerise with E protein, Pax, and Ets transcription factors, preventing the formation of DNA-binding transcription complexes [17]. Via their role in inhibiting differentiation and promoting 'stemness' and cell proliferation, ID proteins have been implicated in tumour progression in a variety of cancers [18]. ALDH3A1 (aldehyde dehydrogenase 3A1) belongs to the ALDH superfamily consisting of 19 members. In addition to their role in converting both cytotoxic endogenous and exogenous aldehydes to their corresponding carboxylic acids in an $\mathrm{NAD}(\mathrm{P})^{+}$- dependent manner [19], ALDH activity is a commonly used marker for identifying cancer cell populations with increased stem or stem-like properties $[20,21]$. Although the majority of these studies have focussed on ALDH1A1, ALDH3A1 has been reported to be upregulated in prostate cancer stem cells and in metastatic lesions compared with primary tumours [22] as well as being required for stem cell maintenance and resistance to cytotoxic drugs [23, 24].

\section{Elevated Id2 and Aldh3a1 expression promotes tumour cell colonisation in the brain}

To assess whether Id2 and/or Aldh3a1 play a role in promoting the growth of tumour cells in the brain, 4T1-Luc cells were transduced with lentiviruses containing non-targeting control shRNA (shNTC) or shRNAs targeting Id2 (shId2) or Aldh3a1 (shAldh3a1) (Fig. 2a) and inoculated intracranially into BALB/c mice. Ex-vivo IVIS imaging of the brains post-mortem revealed a significant reduction in tumour burden in both the shId2 and shAldh3a1 groups (Fig. 2b). This finding was confirmed by histological examination of brain sections (Fig. 2c). Although these data indicate that Id2 and Aldh3a1 expression is required for efficient tumour growth in the brain, they do not address whether these genes play a role in promoting brain colonisation of tumour cells from the circulation. Due to the lack of mouse models with which to reproducibly monitor spontaneous breast cancer metastasis, we ectopically expressed Id2 or Aldh3a 1 in mouse 4T1-Luc cells and in the human breast cancer cell line, MDAMB-231-Luc (Fig. 3a), and performed intracardiac inoculation of the manipulated cells into BALB/c and NSG mice, respectively. For the 4T1-Luc cells, ectopic expression of Aldh3a1 resulted in a significant increase in tumour cell colonisation of the brain as monitored by ex-vivo IVIS imaging. Increased $I d 2$ expression also increased brain colonisation but this did not reach significance (Fig. 3b). However, examination of brain sections revealed that, compared with the control cells, cells with either ectopic Id 2 or Aldh3a1 expression were better spread into the perivascular space of the brain parenchyma (Fig. 3b, right panels). Consistent with the gene expression profiling (Fig. 1), ectopic expression of either Id 2 or Aldh $3 a 1$ had no impact on the level of tumour burden in the lung (Fig. 3c, left panel) but significantly increased tumour burden in the brain (Fig. 3c, middle and right panels). Finally, we examined the distribution of tumour cells in the brain by costaining sections with the endothelial markers endomucin and CD31, and an antibody against human lamin $\mathrm{A} / \mathrm{C}$ to detect the MDA-MB-231-Luc cells. As has been previously reported [25-28], the majority of tumour cells had extravasated into the brain parenchyma and were growing in the perivascular space (Fig. 3d).

\section{Elevated ID2 expression associates with poor outcome in patients with brain metastases}

Next, we addressed the clinical relevance of these findings for human breast cancer patients. Examination of the TCGA breast cancer dataset revealed higher levels of ID2 and ALDH3A1 expression in triple-negative $\left(\mathrm{ER}^{-} /\right.$ $\mathrm{PR}^{-} / \mathrm{HER} 2^{-}$) breast cancers compared with $\mathrm{HER}^{+}$and $\mathrm{ER}^{+} / \mathrm{HER} 2^{-}$breast cancers (Fig. $4 \mathrm{a}$ ), and in $\mathrm{ER}^{-}$versus $\mathrm{ER}^{+}$breast cancers (Fig. 4b). Moreover, in $\mathrm{ER}^{-}$breast cancers, elevated expression of either ID2 or ALDH3A1 was associated with reduced distant metastasis-free survival (Fig. 4c). More importantly, elevated expression of ID2 was associated with reduced brain metastasis free-survival, whereas there was no significant association of $A L D H 3 A 1$ expression levels with outcome in these patients (Fig. 4d). Consistent with our mouse experimental studies demonstrating elevated $I d 2$ expression in cells isolated from brains compared with primary tumours (Fig. 1g), interrogation of human datasets containing gene expression profiling of primary breast cancer and breast cancer brain metastases revealed a significantly increased level of ID2 expression in the brain samples (Fig. 4e). As a consequence, we focussed the remainder of our studies on ID2. 

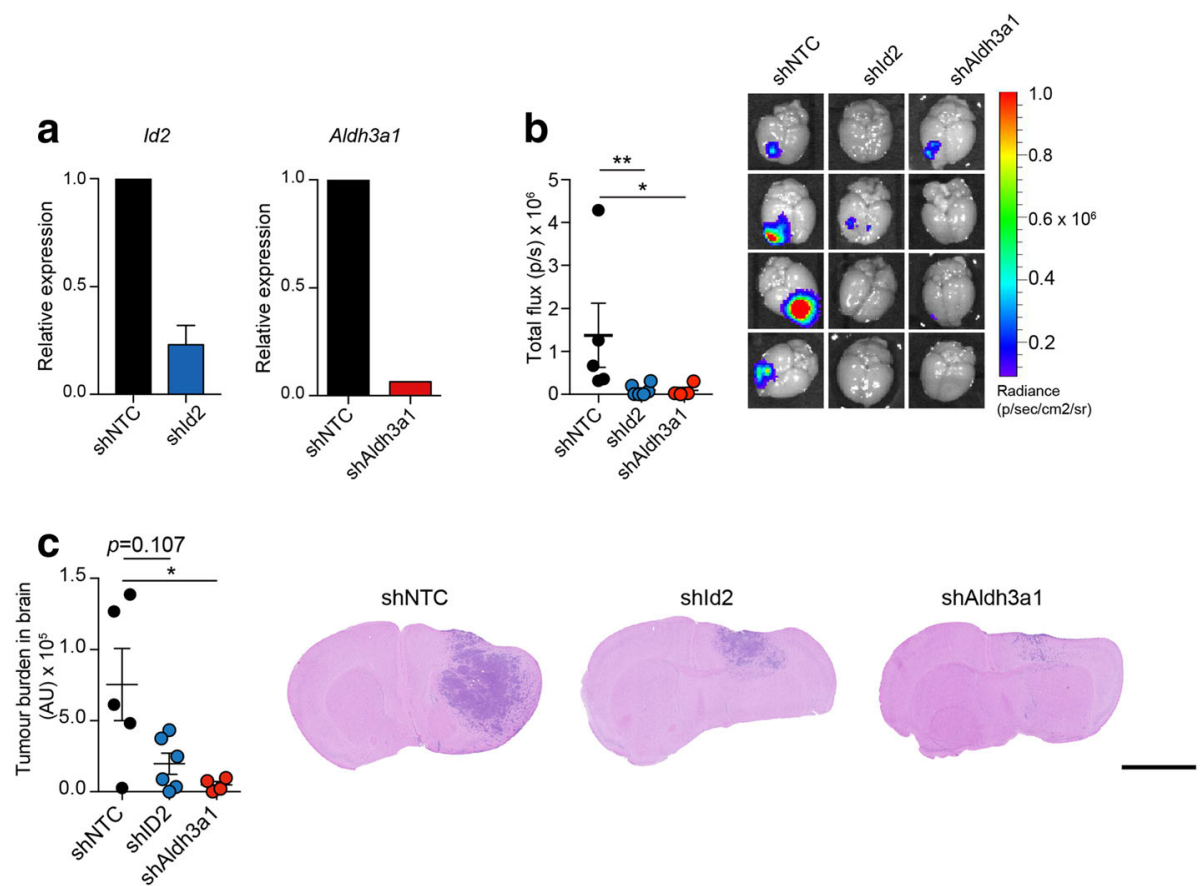

Fig. 2 Downregulation of Id2 or Aldh3a1 expression impairs tumour growth in the brain. a RT-qPCR analysis of Id2 (left panel) and Aldh3a1 (right panel) expression in 4T1-Luc cells transduced with lentiviral non-targeting control (shNTC) small hairpin RNA (shRNA) or shRNAs targeting Id2 (shld2) or Aldh3a1 (shAldh3a1), $n=3$. b $1 \times 10^{4}$ 4T1-Luc cells were inoculated intracranially into BALB/C mice, $n=4-6$ mice per group \pm SEM. ${ }^{* *} p<0.01,{ }^{*} p<0.05$, Kruskal-Wallis test. At day 9 whole brains were collected at necropsy and subjected to ex-vivo IVIS imaging (left panel), and IVIS images are shown (right panel). c Brains from b were fixed, paraffin embedded, and sectioned for histological (H\&E) quantification of tumour burden (left panel). Mean \pm SEM. ${ }^{*} p<0.05$, Kruskal-Wallis test. Right panel shows representative histological sections. Scale bar $=2.5 \mathrm{~mm}$

\section{BMP7 signalling promotes Id2 expression and enhances cell survival}

It has been reported previously that ID2 expression is positively regulated by BMP7 signalling but negatively regulated by TGF $\beta 1[29,30]$. Interestingly, in nontumour-bearing mice, $B m p 7$ expression is substantially higher in the brain than the lungs, whereas the expression of $T g f b 1$ is higher in the lungs compared with the brain (Fig. 5a). Examination of publicly available datasets revealed a significant enrichment of $B m p 7$ expression in brain astrocytes compared with microglia or neurons (Fig. 5b). To directly address whether BMP7 can induce $I d 2$ expression in the tumour cells, 4T1-Luc cells were untreated or treated for 2 to $24 \mathrm{~h}$ with either BMP7 or TGF $\beta 1$. BMP7, but not TGF $\beta 1$, treatment promoted a profound increase in Id2 mRNA levels (Fig. 5c). Moreover, this elevated expression persisted for up to 5 days after the removal of BMP7. These effects were not restricted to the mouse 4T1-Luc cells since equivalent results were obtained with the MDA-MB-231 cells (Fig. 5e, f). We also investigated the expression of other Id family members, Id $1, I d 3$, and Id4. All family members showed elevated expression in the 4T1-Luc sublines isolated from the brains of tumour-bearing mice compared with the lungs or primary tumour sublines (Fig. 5 g). In addition, expression of $I d 1$ and $I d 3$, and to a lesser extent Id4, was dramatically elevated following BMP7, but not TGF 31 , treatment (Fig. 5h).

Finally, we determined the mechanism by which Id2 might promote colonisation of the brain. Tumour cells disseminating to the brain will find themselves in a foreign environment and, in particular, an environment devoid of many of the extracellular matrix components found in primary tumours or in the lungs [31]. To mimic a matrixpoor environment, 4T1-Luc cells were cultured in low-adherence plates. Under these conditions, either ectopic expression of Id2 (Fig. 6a) or treatment with BMP7 to induce $I d 2$ expression (Fig. $6 \mathrm{~b}$ ) resulted in a higher proportion of non-apoptotic 4T1-Luc cells remaining after $24 \mathrm{~h}$. To extend these observations, 4T1-Luc cells were cultured as three-dimensional tumour spheroids by plating cells into low-adherence U-bottomed plates (Fig. 6c). Treatment with BMP7 of either 4T1-Luc parental cells, 4T1-Luc cells transduced with empty vector (Vec), or with a non-targeting control shRNA (shNTC) resulted in increased viability of cells within the spheroids. Conversely, knockdown of $I d 2$ expression (shId2) impaired viability and impaired the ability to respond to BMP7 treatment. 

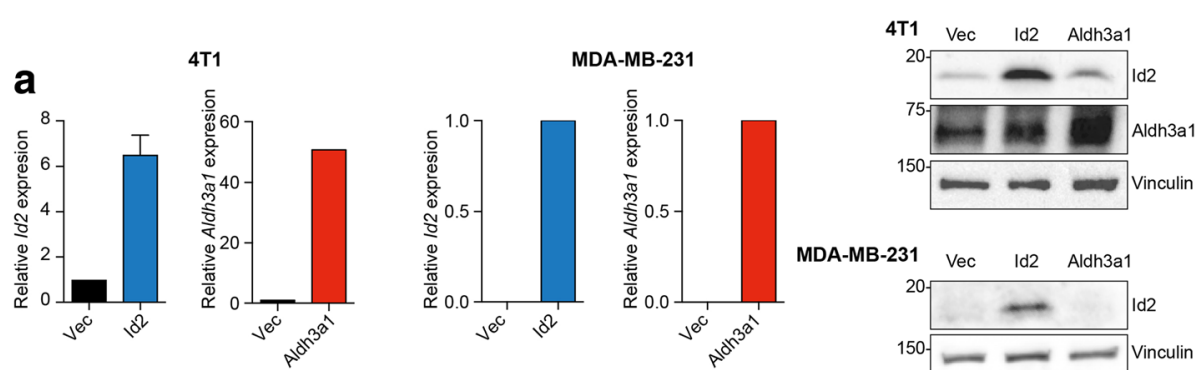

MDA-MB-231
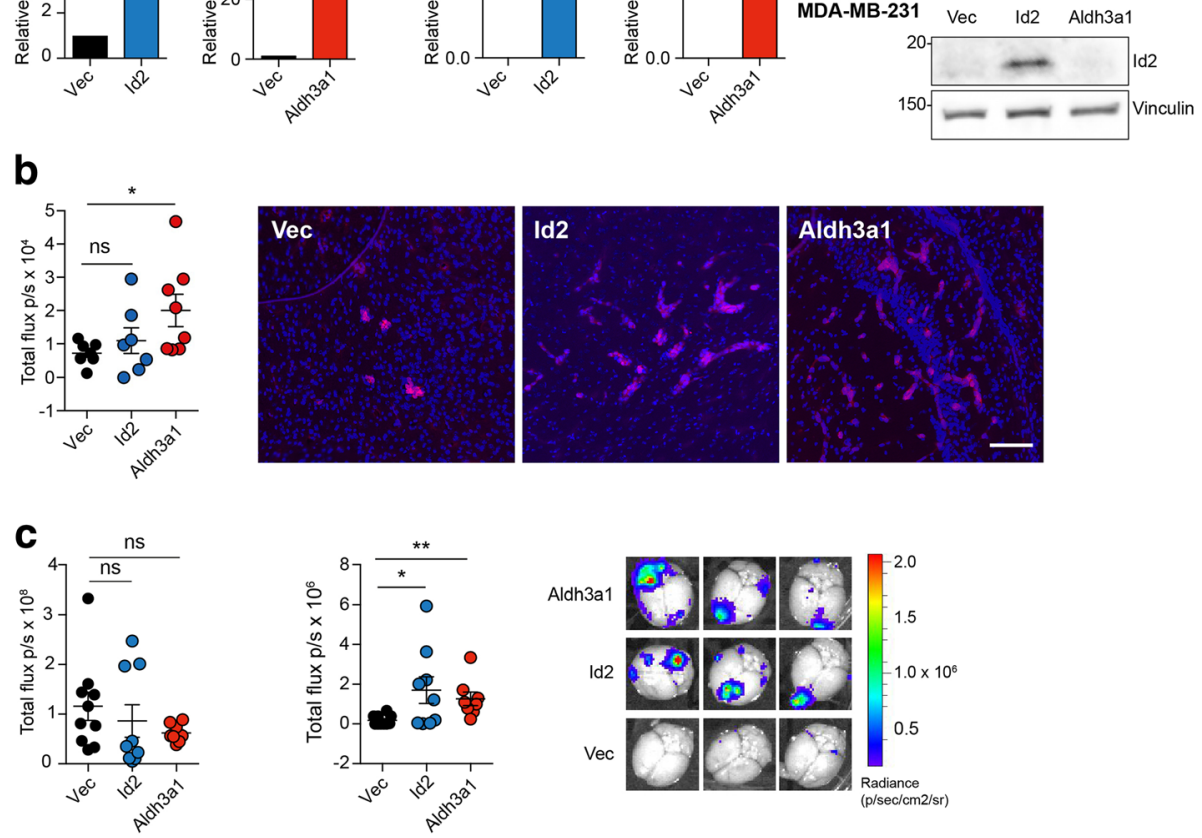

d
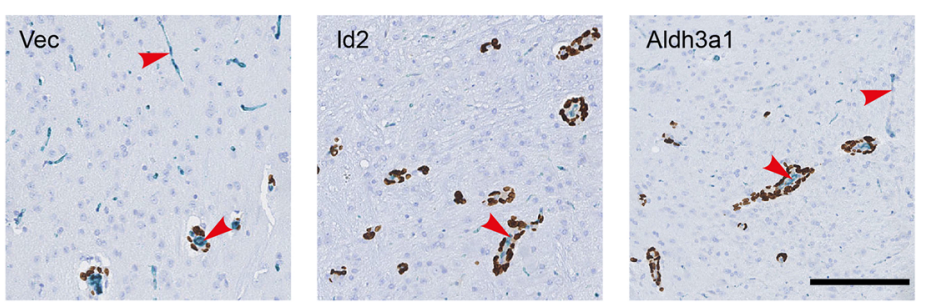

Fig. 3 Increased Id2 or Aldh3al expression enhances metastatic colonisation of the brain following intracardiac inoculation. a 4T1-Luc or MDA-MB-231 cells with ectopic expression of Id2 or Aldh3al or transduced with mCherry vector (Vec) alone. Left panels show RT-qPCR analysis of Id2 and Aldh3al expression. Right panel shows Id 2 and Aldh3a1 protein levels assessed by immunoblotting. $\mathbf{b}$ BALB/C mice inoculated via the left ventricle with $5 \times 10^{4}$ 4T1-Luc cells, $n=7$ or 8 mice per group. At day 9, whole brains were collected at necropsy and subject to ex-vivo IVIS imaging. Mean \pm SEM. ${ }^{*} p<0.05$, Kruskal-Wallis test. Right panel shows representative images of mCherry fluorescent tumour cells in brain sections. Scale bar $=100 \mu \mathrm{m}$. $\mathbf{c} 3 \times 10^{5} \mathrm{MDA}$ MB-231-Luc cells were inoculated into the left ventricle of NSG mice, $n=9$ to 10 mice per group and the experiment terminated on day 23, with organs subject to ex-vivo IVIS imaging. Shown are quantification of ex-vivo IVIS signals in the lungs (left panel, $p=$ ns) and brains (middle panel, ${ }^{*} p<0.05,{ }^{* *} p<0.01$ ), Kruskal-Wallis test. Right panel shows representative IVIS images of brains. $\mathbf{d}$ Sections of fixed and paraffin-embedded brains from c were co-stained for endothelial cell markers endomucin and CD31 (both in blue) and the human nuclear envelope marker lamin A/C (brown). Scale bar $=100 \mu \mathrm{m}$. Arrowheads indicate endomucin/CD31 stained vasculature. ns not significant

\section{Discussion}

In this study, we generated a set of $4 \mathrm{~T} 1$ sublines derived from primary tumours and from tumour cells that had spontaneously disseminated to either the brain or lungs of BALB/C mice. By pair-wise gene-expression profiling, we sought to identify differentially expressed transcripts specifically associated with metastasis to the brain. Moreover, as these sublines were derived in the context of a spontaneous metastasis model where the number of circulating tumour cells reaching secondary sites is very limited, we reasoned that differentially expressed genes were more likely to be involved in survival of cells in the brain and the early stages of metastatic colonisation rather than the expansion of established macrometastatic disease.

Two differentially expressed genes were selected for in-vivo validation, Aldh3a1 and Id2. Downregulation of either gene resulted in reduced tumour burden following intracranial inoculation whereas ectopic expression in either mouse or human tumour cells resulted in increased 

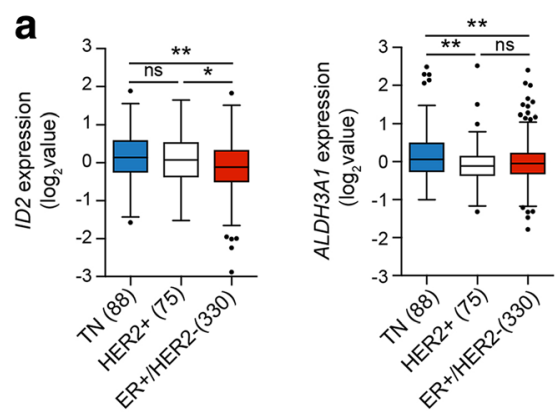

C

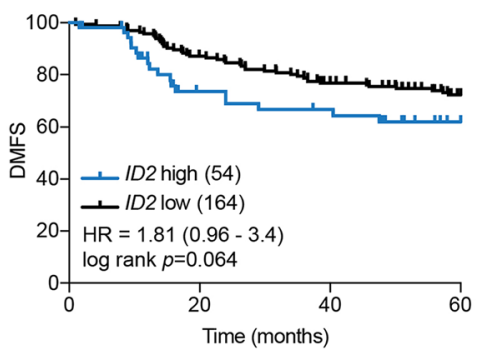

d

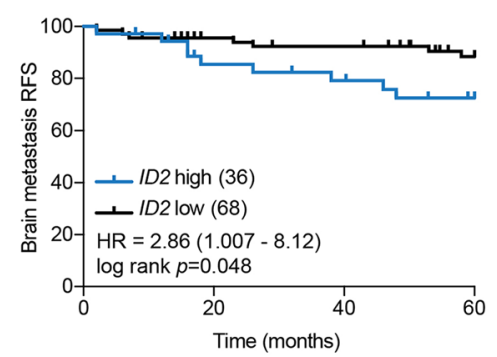

$\mathbf{e}$

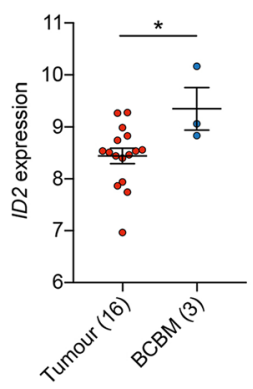

b
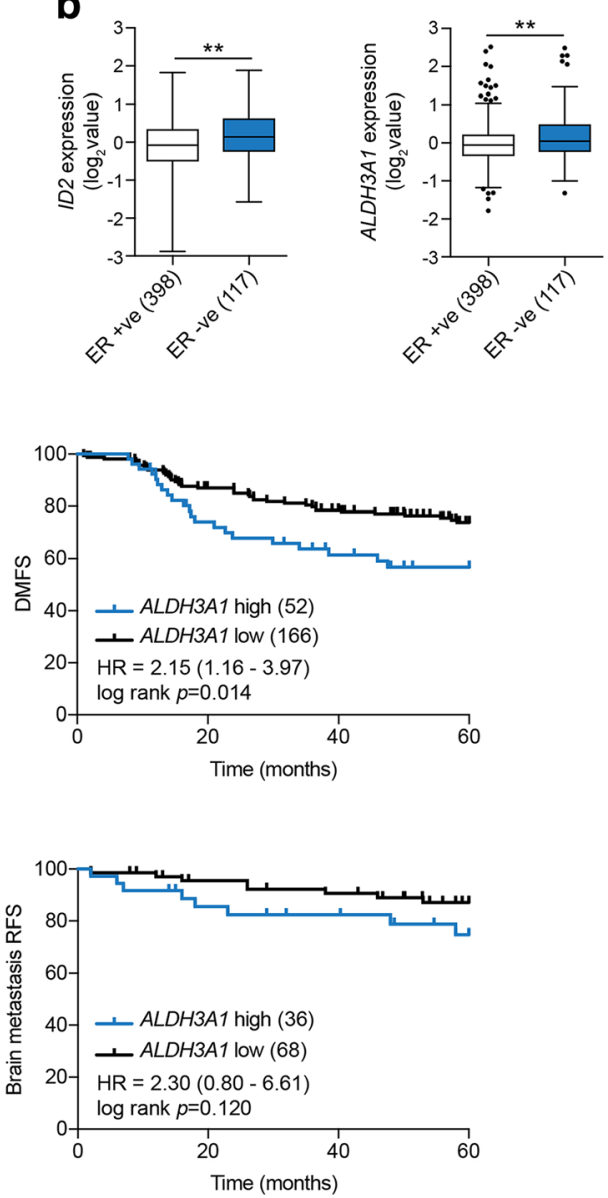

Fig. 4 Elevated ID2 expression correlates with poor patient outcome. a,b Tukey plots representing the expression of ID2 and ALDH3A1 in the TCGA datasets based on receptor status. Box indicates the first and third quartiles, the bar indicates the median, whiskers indicate 1.5 interquartile range (IQR), and dots indicate outliers. The number of samples is shown in parentheses. a Adjusted $p$ values determined using one-way ANOVA followed by Tukey's multiple comparisons test. ${ }^{* *} p<0.01,{ }^{*} p<0.05$. b $p$ values determined using Mann-Whitney test $(p<0.0016$ for ID2, $p<0.0028$ for ALDH3A1). c Kaplan-Meier analysis of breast cancer-specific distance metastasis-free survival (DMFS) in the 218 oestrogen receptor (ER)-negative tumours of the Gyorffy et al. dataset [13]. The number of samples in each group, hazard ratios (HR), and log rank Mantel-Cox $p$ values are shown. $\mathbf{d}$ Kaplan-Meier analysis of brain metastasis relapse-free survival (RFS) in the cohort of 104 ER-negative tumours from patients who had either no metastatic relapse or brainonly relapse (see Methods). HR and log rank Mantel-Cox $p$ values are shown. e Comparison of ID2 expression in primary breast cancers and breast cancer brain metastases (BCBM) in the Schulten et al. [15] (left panel) and Harrell et al. [16] (right panel) datasets. The number of samples is shown in parentheses. Data represent normalised expression values \pm SEM. HER2 human epidermal growth factor 2 , ns not significant, TN triple-negative 

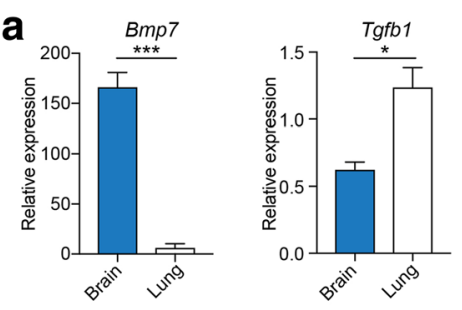

C

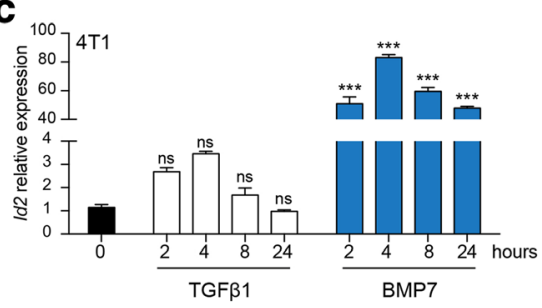

e
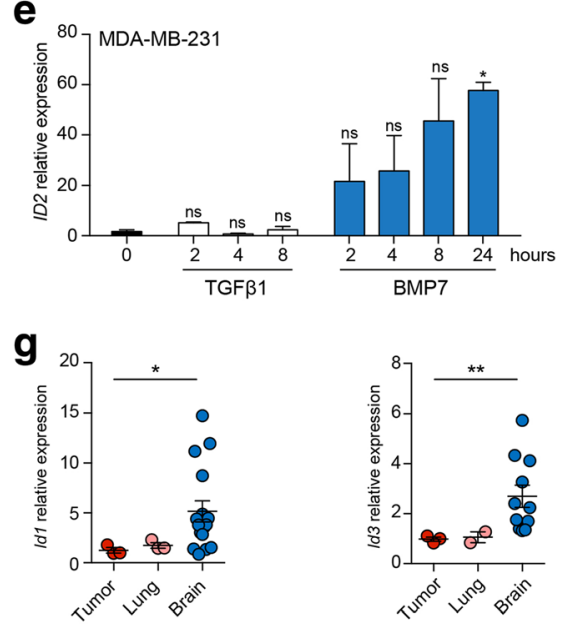

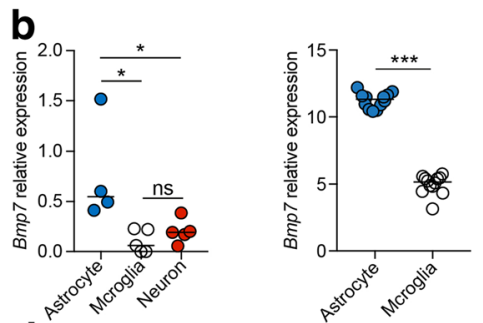

d

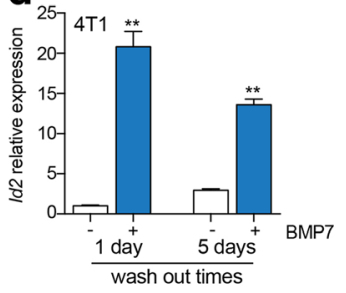

f
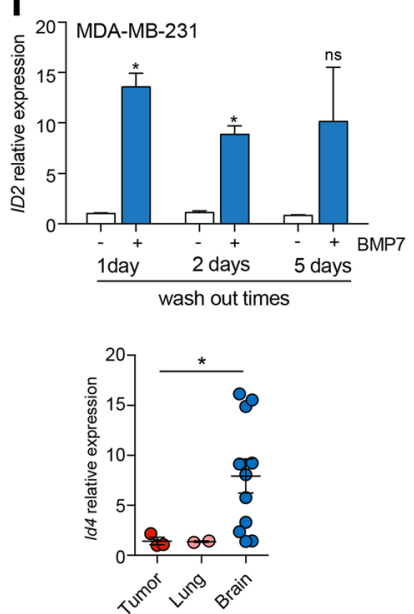

h

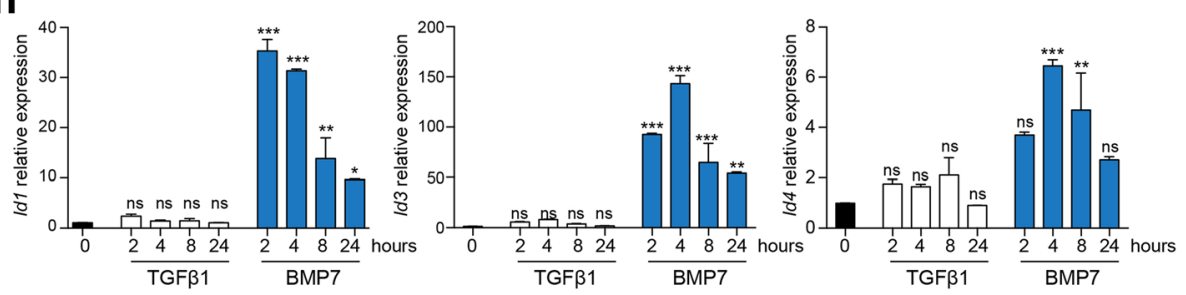

Fig. 5 ld 2 expression is induced by bone morphogenetic protein (BMP)7 but not transforming growth factor (TGF) $\beta 1$. a RT-qPCR analysis of Bmp7 and Tgfb1 expression in brains and lungs from naive BALB/c mice ( $n=3$ independent samples). ${ }^{* *} p<0.001,{ }^{*} p<0.05$, Student's $t$ test. b Expression levels of Bmp7 in mice cell types isolated from non-tumour-bearing mice in the Srinivasan RNAseq dataset [11] (GSE75246; $n=4$ or 5 samples per cell type) and Kamphuis dataset [12] (GSE74614; $n=12$ samples per cell type). Scatter plots represent median. ${ }^{*} p<0.05,{ }^{* * *} p<0.001$, Mann Whitney test. c RT-qPCR analysis of Id2 expression in 4T1-Luc cells treated with recombinant TGF $31(5 \mathrm{ng} / \mathrm{mL})$ or BMP7 (300 ng/mL) for $2-24 \mathrm{~h}$. Data represent 2 wells/ condition, mean \pm SEM, and are shown relative to the untreated sample. ${ }^{* *} p<0.001$, one-way ANOVA. d 4T1-Luc cells were treated with BMP7 (300 ng/ $\mathrm{mL}$ ) for $24 \mathrm{~h}$ and cells were washed and incubated in complete media for a further 1 or 5 days before Id 2 expression was assessed by RT-qPCR. Data represent 2 wells/condition, mean \pm SEM. ${ }^{* *} p<0.01$, Student's $t$ test. e,f ID2 expression levels in MDA-MB-231-Luc cells treated as described in b and $c .{ }^{*} p<0.05$, one-way ANOVA and Student's $t$ test. g RT-qPCR analysis of Id 1 , Id3, and Id4 expression in 4T1Luc tumour sublines independently isolated from primary tumours, lungs, and brains, relative to Gapdh. $p$ values generated using MannWhitney test between tumour and brain. ${ }^{*} p<0.05,{ }^{*} p<0.01$ (lungs were not included in statistical analysis as $n=2$ samples). $\mathbf{h}$ RT-qPCR analysis of $/ d 1$, Id3, and $/ d 4$ expression levels in 4 T1-Luc cells treated with TGF $\beta 1(5 \mathrm{ng} / \mathrm{mL})$ or BMP7 $(300 \mathrm{ng} / \mathrm{mL})$ for $2-24 \mathrm{~h}$. Data represent 2 samples per time point, mean \pm SEM and are shown relative to untreated samples. ${ }^{*} p<0.05,{ }^{* *} p<0.01,{ }^{* * *} p<0.001$, one-way ANOVA. ns not significant 

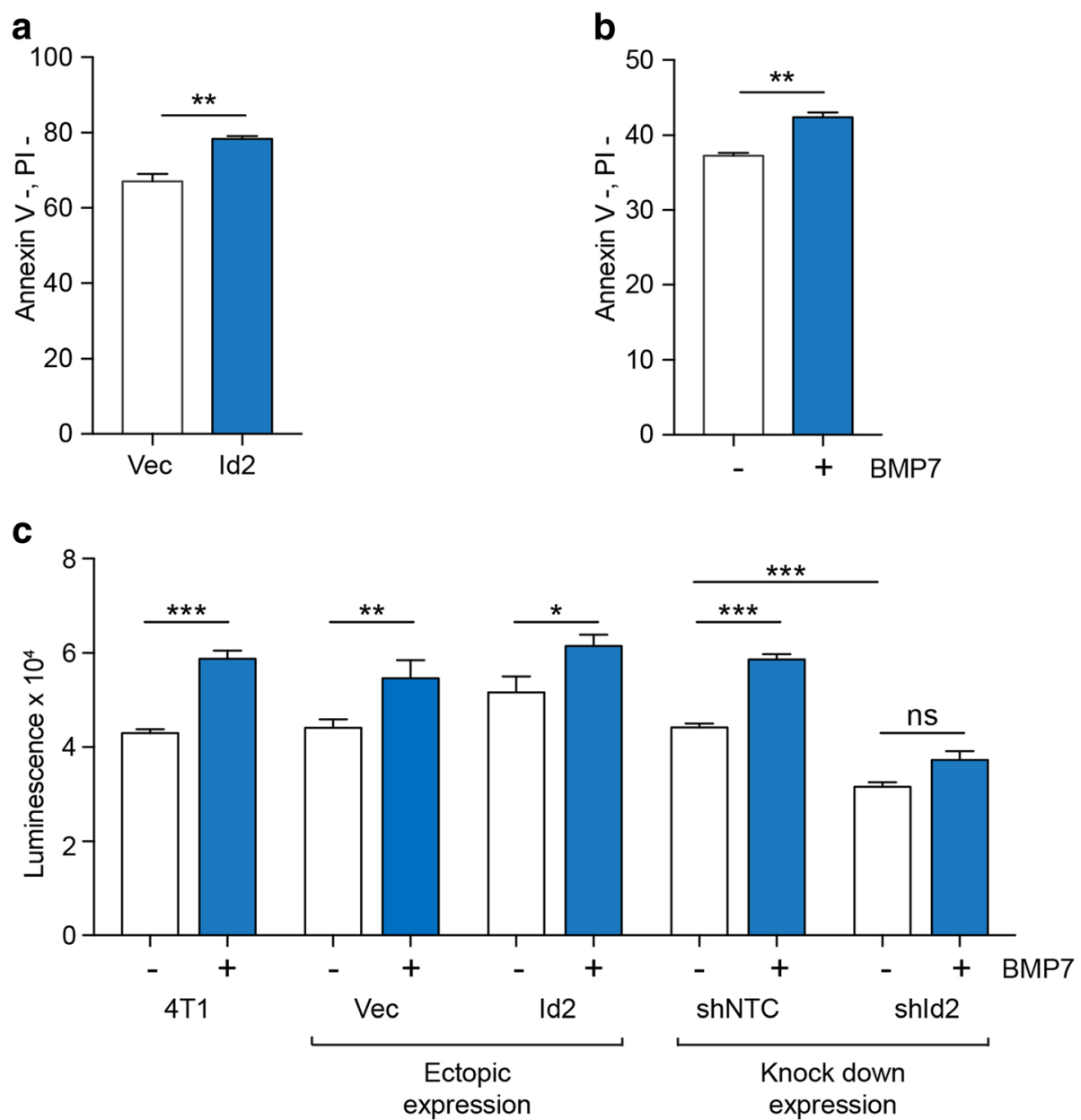

Fig. 6 Id2 expression protects against apoptosis. a $5 \times 10^{4} 4 \mathrm{~T} 1$-Luc cells expressing vector alone (Vec) or with ectopic expression of Id2 were cultured in six-well low-adherence plates in 2\% FBS for $24 \mathrm{~h}$ before annexin V/PI staining. Data shown as percent of healthy cells (annexin $\mathrm{V}^{-}$, $\mathrm{PI}^{-}$) remaining, $n=3$. Mean \pm SEM. ${ }^{* *} p<0.01$, Student's $t$ test. $\mathbf{b}$ Parental $4 \mathrm{~T} 1$-Luc cells cultured in suspension as described in a in the presence of absence of bone morphogenetic protein (BMP)7 $(300 \mathrm{ng} / \mathrm{mL})$ for $24 \mathrm{~h}$ prior to annexin V/PI staining. Data shown as percent of healthy cells (annexin $\mathrm{V}^{-}, \mathrm{PI}^{-}$) remaining, three samples per condition. Mean \pm SEM. ${ }^{* *} p<0.01$, Student's $t$ test. c 750 parental $4 \mathrm{~T} 1$-Luc cells (4T1) or $4 \mathrm{~T} 1$-Luc cells transduced with empty vector (Vec) or with ectopic expression of Id2, or 4T1-Luc cells transduced with non-targeting control short hairpin RNA (shNTC) or shRNA targeting Id2 (shld2) were sorted into low-adherence 96-well U-bottomed plates in DMEM plus 2\% FBS and cultured in the presence or absence of BMP7 (300 ng/mL) for 7 days before viability was monitored by CellTiter-Glo. Data from $n=5$ wells $/$ sample. ${ }^{*} p<0.05,{ }^{* *} p<0.01$, ${ }^{* * *} p<0.001$, two-way ANOVA with Tukey's post-test. ns not significant

metastatic burden in the brain following intracardiac inoculation but did not promote increased metastasis to the lung.

Tumour cells colonising the brain face unique challenges. First, the tumour cells have to navigate across the blood-brain barrier that separates the brain from the general circulation [32]. Second, the cellular and non-cellular composition of the brain is distinct from that found both in the primary tumour and at other metastatic sites. For example, tumour cells metastasising to the brain have to avoid apoptosis mediated by astrocyte-secreted Fas ligand $[26,33]$ and detection and elimination by reactive microglia [6]. Similarly, the absence of stromal fibroblasts and fibrillar collagen [31] means that infiltrating tumour cells have to adapt to the foreign extracellular matrix composition. Finally, successful metastasising cells have to adapt to an altered metabolic environment [7, 34]. The brain consumes $\sim 20 \%$ of the body's glucose-derived energy but, when blood glucose is low, the brain can adapt its metabolism to use acetate, ketone bodies, or fatty acids as alternative fuels. Metastasising tumours cells need to have metabolic flexibility to survive in this environment.

As has been reported in other studies [25-28], in the models used here it was observed that tumour cells that disseminated to the brain parenchyma remained closely located to the brain capillaries (see Fig. 3). It is now well established that cancer stem cells reside in niche microenvironments, including perivascular niches in the brain 
[35], and that these niches serve to maintain the tumour cell 'stemness' [36]. As both ID2 and ALDH3A1 have been implicated in promoting stem cell-like features in tumour cells [18, 24, 37], their elevated expression may provide an advantage in the early stage of metastatic colonisation by retaining cells in the niche until they are ready to face the full challenges of the brain microenvironment. In addition, among the ALDH family, ALD H3A1 has a specific role in peroxidic aldehyde metabolism $[24,38]$. In metabolically challenging conditions, particularly in conditions of high oxidative stress, production of reactive oxygen species (ROS) leads to peroxidation of lipids, which in turn gives rise to cytotoxic lipid aldehydes. The ability of ALDH3A1 to function as lipid aldehyde scavenger [39] would provide a survival advantage for disseminating tumour cells encountering adverse conditions. However, it was notable in this study that, when expression of $A L D H 3 A 1$ was examined in breast cancer clinical datasets, high expression was significantly associated with an increased risk of distant metastatic relapse but not with brain-specific relapse (Fig. 4c, d). Consequently, although the models used in this study identified increased Aldh3a1 expression to be associated with increased brain but not lung metastasis, the clinical data point to a more general pro-metastatic function. In contrast, ID2 expression in clinical samples correlated with increased distant metastatic relapse and brain-specific metastatic relapse.

ID proteins are negative regulators of basic HLH (bHLH) transcription factors and, additionally, ID2 can bind and over-ride the tumour suppressor function of retinoblastoma (RB) tumour suppressor. In normal cells, these activities underpin the role of ID proteins in inhibiting cell differentiation and promoting cell proliferation. In cancers, ID proteins are found at a higher level than in normal adult tissues where they function to sustain self-renewal of stem or stem-like cancer cells and inhibit apoptosis and entry of tumour cells into senescence [17, 18]. For ID2 it has been shown that expression is required to maintain glioma [40], glioblastoma [41], head and neck [42], and colorectal cancer stem/stem-like cells. Previously it has been demonstrated in normal mouse mammary cells and other non-transformed epithelial cell types that exposure to TGF $\beta$ resulted in decreased ID2 mRNA and protein levels, whereas BMP7 could both over-ride the TGF $\beta$-mediated ID2 repression and, on its own, promote increased ID2 expression [29, 30, 43]. BMPs are members of the TGF $\beta$ superfamily but, whereas TGF $\beta$ s bind to the TGF $\beta$ type 1 receptors ALK1 and ALK5, BMPs bind to BMP-specific ALK receptors, with BMP7 binding to ALK2 [44].

Given the role reported here for ID2 in promoting breast cancer metastasis to the brain, it was striking that, although levels of $T g f b 1$ mRNA were approximately two-fold higher in the normal mouse lung compared with the brain, levels of $B m p 7$ mRNA were $>100$-fold higher in the brain compared with the lung. Moreover, whereas treatment with TGF $\beta 1$ had little impact on ID2 expression in either mouse mammary carcinoma or human breast cancer cells, BMP7 treatment resulted in a > 50 -fold increase in ID2 mRNA levels and this level of expression was sustained for at least 5 days following BMP7 withdrawal. Together with the demonstration that increased $I d 2$ expression protects tumour cells from loss of attachment-induced anoikis and promotes growth of three-dimensional tumour spheroids, the data presented here support a model in which spontaneously metastasising breast cancers cells with higher ID2 expression will have a survival advantage when they disseminate to the brain and that, once in the brain, cells that are receptive to BMP7 signalling to maintain high-level ID2 expression will be better able to progress to macrometastatic disease by tolerating the harsh pro-apoptotic brain microenvironment.

\section{Conclusions}

The incidence of brain metastasis in breast and other cancers is increasing, yet patient prognosis after a diagnosis of metastatic relapse in the brain remains dismal. This situation is further compounded by the lack of prospective clinical trial data to assess the efficacy of current system therapies in patients with brain metastases [1]. In addition, there is an urgent need to develop methodologies for the identification of patients at high risk of developing brain metastasis and to better understand the unique biology associated with tumour cell colonisation of the brain to identify potential new therapeutic strategies. Using a model that more faithfully recapitulates the dissemination of tumour cells to secondary sites, combined with in-vivo and in-silico validation studies, we identified ID2 as a promising brain metastasis promoter. Future studies will be required to assess whether monitoring ID2 mRNA or protein levels in primary tumours or in plasma samples could provide a prognostic biomarker for patients at higher risk of relapse in the brain. Finally, it is well documented that ID family proteins play a key role in developmental processes and that expression is downregulated in most normal adult tissues but can be re-activated in cancer cells $[17,18]$. Although this pattern of expression makes ID proteins potential therapeutic targets, helix-loop-helix proteins are typically described as 'undruggable'. However, in recent years there have been rapid technological advances in developing inhibitors of protein-protein interaction as well as approaches for targeted protein degradation such as proteolysis targeting chimaeras (PROTACs), bifunctional molecules for hijacking E3 ligases or small 
molecules that redirect E3 ligase activity [45]. The development of reagents that can inhibit ID2 dimerisation or promote its degradation will, in the future, allow robust assessment of ID2 as a potential therapeutic target to prevent or limit the development of breast cancer brain metastasis.

\section{Additional file}

Additional file 1: Table S1. MISSION shRNA pLKO-puro transduction particles. Table S2. Open Reading Frame Clone Expression Systems (Genecopoeia). Table S3. Taqman RT-qPCR gene expression assays. Table S4. Antibodies used for immunoblotting (B) and immunohistochemistry $(\mathrm{IHC})$. Figure S1. Higher power image of heat map of differentially expressed genes from Fig. 1C. Figure S2. Heat map of shortlisted genes. (PDF $1540 \mathrm{~kb}$ )

\section{Abbreviations}

ATCC: American Type Culture Collection; B2M: Beta-2-microglobin; BMP: Bone morphogenetic protein; ER: Oestrogen receptor; FACS: Fluorescence-activated cell sorting; FBS: Fetal bovine serum; FFPE: Formalin-fixed paraffin-embedded; GAPDH: Glyceraldehyde-3-phosphate dehydrogenase; H\&E: Haematoxylin and eosin; H2B-mRFP: Histone H2B-monomeric red fluorescent protein; HER2: Human epidermal growth factor receptor 2; IVIS: In-vivo imaging system; MOI: Multiplicity of infection; NSG: NOD SCID gamma; ORF: Open reading frame; PR: Progesterone receptor; RT-qPCR: Quantitative reverse-transcription polymerase chain reaction; shRNA: Short hairpin RNA; STR: Short tandem repeats; TCGA: The Cancer Genome Atlas; TGF: Transforming growth factor

\section{Acknowledgements}

We thank Syed Haider and his team at The Breast Cancer Now Toby Robins Research Centre Bioinformatics Core and Nina Barough Pathology Facilities, and ICR FACS and Light Microscopy Facility for support in this project. We thank David Mansfield for help with the Vectra pathology imaging system and Jakub Mieczkowski for support in gene expression analysis. Gene expression profiling was performed by Cambridge Genomic Services.

\section{Funding}

This work was funded by Breast Cancer Now (CTR-Q4-Y3), working in partnership with Walk the Walk to CMI. We acknowledge NHS funding to the NIHR Biomedical Research Centre at The Royal Marsden and the ICR.

\section{Availability of data and materials}

Gene expression data are deposited at GEO with accession number GSE110101. Other datasets analysed in the support of this study have been referenced.

\section{Authors' contributions}

Experimental data were provided by MK, Ml, CV, FT, AF, and AvW. Bioinformatics analysis was performed by QG and FT. MK and CMI devised and oversaw the project. MK, MI, and CMI wrote the manuscript with input from all other authors. All authors read and approved the final manuscript.

\section{Ethics approval}

All animal work was carried out under UK Home Office Project licenses 70/ 7413 and P6AB1448A (Establishment License, X702B0E74 70/2902) and was approved by the Animal Welfare and Ethical Review Body at The Institute of Cancer Research.

\section{Consent for publication}

Not applicable.

\section{Competing interests}

The authors declare that they have no competing interests.

\section{Publisher's Note}

Springer Nature remains neutral with regard to jurisdictional claims in published maps and institutional affiliations.

\section{Author details}

${ }^{1}$ The Breast Cancer Now Toby Robins Research Centre, The Institute of Cancer Research, 237 Fulham Road, London SW3 6JB, UK. ${ }^{2}$ Present address: Oncology Cell Therapy DPU, GSK, Gunnels Wood Road, Stevenage SG1 2NY, UK. ${ }^{3}$ Present address: Division of Tumor Biology \& Immunology, The Netherlands Cancer Institute, Plesmanlaan 121, 1066, CX, Amsterdam, The Netherlands.

Received: 12 December 2018 Accepted: 21 December 2018

Published online: 14 January 2019

\section{References}

1. Witzel I, Oliveira-Ferrer L, Pantel K, Muller V, Wikman H. Breast cancer brain metastases: biology and new clinical perspectives. Breast Cancer Res. 2016;18(1):8.

2. Bachmann C, Schmidt S, Staebler A, Fehm T, Fend F, Schittenhelm J, Wallwiener D, Grischke E. CNS metastases in breast cancer patients: prognostic implications of tumor subtype. Med Oncol. 2015;32(1):400.

3. Valiente M, Ahluwalia MS, Boire A, Brastianos PK, Goldberg SB, Lee EQ, Le Rhun E, Preusser M, Winkler F, Soffietti R. The evolving landscape of brain metastasis. Trends Cancer. 2018;4(3):176-96.

4. Niikura N, Hayashi N, Masuda N, Takashima S, Nakamura R, Watanabe K, Kanbayashi C, Ishida M, Hozumi Y, Tsuneizumi M, et al. Treatment outcomes and prognostic factors for patients with brain metastases from breast cancer of each subtype: a multicenter retrospective analysis. Breast Cancer Res Treat. 2014;147(1):103-12.

5. Owonikoko TK, Arbiser J, Zelnak A, Shu HK, Shim H, Robin AM, Kalkanis SN, Whitsett TG, Salhia B, Tran NL, et al. Current approaches to the treatment of metastatic brain tumours. Nat Rev Clin Oncol. 2014;11(4):203-22.

6. Lorger M. Tumor microenvironment in the brain. Cancers (Basel). 2012;4(1): 218-43.

7. Lowery FJ, Yu D. Brain metastasis: unique challenges and open opportunities. Biochim Biophys Acta. 2017;1867(1):49-57.

8. Quail DF, Joyce JA. The microenvironmental landscape of brain tumors. Cancer Cell. 2017;31(3):326-41.

9. Avgustinova A, Iravani M, Robertson D, Fearns A, Gao Q, Klingbeil P, Hanby AM, Speirs V, Sahai E, Calvo F, et al. Tumour cell-derived Wnt7a recruits and activates fibroblasts to promote tumour aggressiveness. Nat Commun. 2016; 7:10305.

10. Cancer Genome Atlas N. Comprehensive molecular portraits of human breast tumours. Nature. 2012:490(7418):61-70.

11. Srinivasan K, Friedman BA, Larson JL, Lauffer BE, Goldstein LD, Appling LL, Borneo J, Poon C, Ho T, Cai F, et al. Untangling the brain's neuroinflammatory and neurodegenerative transcriptional responses. Nat Commun. 2016;7:11295.

12. Kamphuis W, Kooijman L, Orre M, Stassen O, Pekny M, Hol EM. GFAP and vimentin deficiency alters gene expression in astrocytes and microglia in wild-type mice and changes the transcriptional response of reactive glia in mouse model for Alzheimer's disease. Glia. 2015;63(6):1036-56.

13. Gyorffy B, Lanczky A, Eklund AC, Denkert C, Budczies J, Li Q, Szallasi Z. An online survival analysis tool to rapidly assess the effect of 22,277 genes on breast cancer prognosis using microarray data of 1,809 patients. Breast Cancer Res Treat. 2010;123(3):725-31.

14. Xing F, Liu Y, Sharma S, Wu K, Chan MD, Lo HW, Carpenter RL, Metheny-Barlow LJ, Zhou X, Qasem SA, et al. Activation of the C-Met pathway mobilizes an inflammatory network in the brain microenvironment to promote brain metastasis of breast cancer. Cancer Res. 2016;76(17):4970-80.

15. Schulten HJ, Bangash M, Karim S, Dallol A, Hussein D, Merdad A, AlThoubaity FK, Al-Maghrabi J, Jamal A, Al-Ghamdi F, et al. Comprehensive molecular biomarker identification in breast cancer brain metastases. J Transl Med. 2017;15(1):269.

16. Harrell JC, Prat A, Parker JS, Fan C, He X, Carey L, Anders C, Ewend M, Perou $C M$. Genomic analysis identifies unique signatures predictive of brain, lung, and liver relapse. Breast Cancer Res Treat. 2012;132(2):523-35.

17. Perk J, lavarone A, Benezra R. Id family of helix-loop-helix proteins in cancer. Nat Rev Cancer. 2005;5(8):603-14.

18. Lasorella A, Benezra R, lavarone A. The ID proteins: master regulators of cancer stem cells and tumour aggressiveness. Nat Rev Cancer. 2014;14(2): 77-91. 
19. Singh S, Brocker C, Koppaka V, Chen Y, Jackson BC, Matsumoto A, Thompson DC, Vasiliou V. Aldehyde dehydrogenases in cellular responses to oxidative/electrophilic stress. Free Radic Biol Med. 2013;56:89-101.

20. Ginestier C, Hur MH, Charafe-Jauffret E, Monville F, Dutcher J, Brown M, Jacquemier J, Viens P, Kleer CG, Liu S, et al. ALDH1 is a marker of normal and malignant human mammary stem cells and a predictor of poor clinical outcome. Cell Stem Cell. 2007;1(5):555-67.

21. Rodriguez-Torres M, Allan AL. Aldehyde dehydrogenase as a marker and functional mediator of metastasis in solid tumors. Clin Exp Metastasis. 2016; 33(1):97-113.

22. Yan J, De Melo J, Cutz JC, Aziz T, Tang D. Aldehyde dehydrogenase 3A1 associates with prostate tumorigenesis. Br J Cancer. 2014;110(10):2593-603.

23. Gasparetto M, Smith CA. ALDHs in normal and malignant hematopoietic cells: potential new avenues for treatment of AML and other blood cancers. Chem Biol Interact. 2017;276:46-51.

24. Muzio G, Maggiora M, Paiuzzi E, Oraldi M, Canuto RA. Aldehyde dehydrogenases and cell proliferation. Free Radic Biol Med. 2012;52(4): 735-46.

25. Lorger M, Felding-Habermann B. Capturing changes in the brain microenvironment during initial steps of breast cancer brain metastasis. Am J Pathol. 2010;176(6):2958-71

26. Valiente M, Obenauf AC, Jin X, Chen Q, Zhang XH, Lee DJ, Chaft JE, Kris MG, Huse JT, Brogi E, et al. Serpins promote cancer cell survival and vascular cooption in brain metastasis. Cell. 2014;156(5):1002-16.

27. Carbonell WS, Ansorge O, Sibson N, Muschel R. The vascular basement membrane as "soil" in brain metastasis. PLoS One. 2009;4(6):e5857.

28. Kienast $Y$, von Baumgarten $L$, Fuhrmann M, Klinkert WE, Goldbrunner $R$, Herms J, Winkler F. Real-time imaging reveals the single steps of brain metastasis formation. Nat Med. 2010;16(1):116-22.

29. Valcourt U, Kowanetz M, Niimi H, Heldin CH, Moustakas A. TGF-beta and the Smad signaling pathway support transcriptomic reprogramming during epithelial-mesenchymal cell transition. Mol Biol Cell. 2005;16(4):1987-2002.

30. Veerasamy M, Phanish M, Dockrell ME. Smad mediated regulation of inhibitor of DNA binding 2 and its role in phenotypic maintenance of human renal proximal tubule epithelial cells. PLoS One. 2013;8(1):e51842.

31. Bellail AC, Hunter SB, Brat DJ, Tan C, Van Meir EG. Microregional extracellular matrix heterogeneity in brain modulates glioma cell invasion. Int J Biochem Cell Biol. 2004:36(6):1046-69.

32. Sevenich L, Bowman RL, Mason SD, Quail DF, Rapaport F, Elie BT, Brogi E, Brastianos PK, Hahn WC, Holsinger LJ, et al. Analysis of tumour- and stromasupplied proteolytic networks reveals a brain-metastasis-promoting role for cathepsin S. Nat Cell Biol. 2014;16(9):876-88.

33. Wasilewski D, Priego N, Fustero-Torre C, Valiente M. Reactive astrocytes in brain metastasis. Front Oncol. 2017;7:298.

34. Lehuede C, Dupuy F, Rabinovitch R, Jones RG, Siegel PM. Metabolic plasticity as a determinant of tumor growth and metastasis. Cancer Res. 2016;76(18):5201-8.

35. Calabrese C, Poppleton H, Kocak M, Hogg TL, Fuller C, Hamner B, Oh EY, Gaber MW, Finklestein D, Allen M, et al. A perivascular niche for brain tumor stem cells. Cancer Cell. 2007;11(1):69-82.

36. Oskarsson T, Batlle E, Massague J. Metastatic stem cells: sources, niches, and vital pathways. Cell Stem Cell. 2014;14(3):306-21.

37. Dong HJ, Jang GB, Lee HY, Park SR, Kim JY, Nam JS, Hong IS. The Wnt/betacatenin signaling/ld2 cascade mediates the effects of hypoxia on the hierarchy of colorectal-cancer stem cells. Sci Rep. 2016;6:22966.

38. Singh M, Kapoor A, Bhatnagar A. Oxidative and reductive metabolism of lipid-peroxidation derived carbonyls. Chem Biol Interact. 2015;234:261-73.

39. Canuto RA, Muzio G, Ferro M, Maggiora M, Federa R, Bassi AM, Lindahl R, Dianzani MU. Inhibition of class-3 aldehyde dehydrogenase and cell growth by restored lipid peroxidation in hepatoma cell lines. Free Radic Biol Med. 1999;26(3-4):333-40.

40. Rahme GJ, Zhang Z, Young AL, Cheng C, Bivona EJ, Fiering SN, Hitoshi $Y$, Israel MA. PDGF engages an E2F-USP1 signaling pathway to support ID2-mediated survival of proneural glioma cells. Cancer Res. 2016;76(10): 2964-76.

41. Lee SB, Frattini V, Bansal M, Castano AM, Sherman D, Hutchinson K, Bruce JN, Califano A, Liu G, Cardozo T, et al. An ID2-dependent mechanism for VHL inactivation in cancer. Nature. 2016;529(7585):172-7.

42. Bae WJ, Koo BS, Lee SH, Kim JM, Rho YS, Lim JY, Moon JH, Cho JH, Lim YC. Inhibitor of DNA binding 2 is a novel therapeutic target for stemness of head and neck squamous cell carcinoma. Br J Cancer. 2017;117(12):1810-8.
43. Siegel PM, Shu W, Massague J. Mad upregulation and Id2 repression accompany transforming growth factor (TGF)-beta-mediated epithelial cell growth suppression. J Biol Chem. 2003;278(37):35444-50.

44. Miyazono K, Miyazawa K. Id: a target of BMP signaling. Sci STKE. 2002; 2002(151):pe40.

45. Collins I, Wang H, Caldwell JJ, Chopra R. Chemical approaches to targeted protein degradation through modulation of the ubiquitin-proteasome pathway. Biochem J. 2017;474(7):1127-47.
Ready to submit your research? Choose BMC and benefit from:

- fast, convenient online submission

- thorough peer review by experienced researchers in your field

- rapid publication on acceptance

- support for research data, including large and complex data types

- gold Open Access which fosters wider collaboration and increased citations

- maximum visibility for your research: over $100 \mathrm{M}$ website views per year

At BMC, research is always in progress.

Learn more biomedcentral.com/submissions 